\title{
KERANGKA KERJA TEKNOLOGI INFORMASI UNTUK AUDIT MUTU INTERNAL BERBASIS IAPS 4.0 DENGAN ACTOR NETWORK THEORY
}

\author{
Suryo Widiantoro ${ }^{1^{*}}$, Yodi $^{1}$ \\ ${ }^{1}$ Prodi Sistem Informasi, Universitas Universal \\ email: *suryo.widiantoro@gmail.com
}

\begin{abstract}
Higher education is an institution engaged in services that provides services to internal and external consumers consisting of students, stakeholders and alumni both academically and non academically. The services provided determine the satisfaction of consumers. Higher education values are manifested in the form of accreditation. The value of accreditation is expected to be in accordance with the quality culture that runs in universities. To ensure customer satisfaction, universities must always evaluate the service policies provided based on established university standards. Evaluation is done by conducting an internal university quality audit. In the future, this activity will be routinely carried out to ensure that activities in higher education are in accordance with the standards set as a process for implementing a higher education quality culture. This is expected to be able to encourage the superior value of higher education accreditation by conducting analysis, costs and providing advice to support decisions by the highest leadership. The application of this framework analysis uses the Actor Network Theory approach to see the relationship between actors in the application of information technology so that the resulting information system is acceptable and in accordance with existing business processes at universal universities. The results of this study are a framework for making information systems based on the results of web-based ANT analysis.
\end{abstract}

Keywords: actor network theory; audit; iaps 4.0; it framework; internal quality of PT

\begin{abstract}
Abstrak: Perguruan tinggi merupakan suatu lembaga yang bergerak dibidang jasa yang memberikan pelayanan kepada para konsumen internal dan eksternal yang terdiri dari mahasiswa, stakeholder dan alumni baik secara akademik dan non akademik. Pelayanan yang diberkan menentukan kepuasan para kosumen. Nilai perguruan tinggi diwujudkan dalam bentuk akreditasi. Nilai akreditasi diharapkan sesuai dengan budaya mutu yang berjalan didalam pergurua tinggi. Untuk menjamin kepuasan konsumen maka, perguruan tinggi harus selalu melakukan evaluasi terhadap kebijakan pelayanan yang diberikan berdasarkan standar perguruan tinggi yang ditetapkan. Evaluasi dilakukan dengan cara melakukan kegiatan audit mutu internal perguruan tinggi. Kegiatan ini kedepannya secara rutin dilakukan untuk memastikan aktivitas didalam perguruan tinggi sesuai dengan standar yang ditetapkan sebagai proses untuk menerapkan budaya mutu perguruan tinggi. Hal ini diharapkan mampu mendorong nilai unggul akreditasi perguruan tinggi dengan melakukan analisis, penilaian dan pemberian saran sebagai pendukung pengambilan keputusan oleh pimpinan tertinggi. Penerapan analisis kerangka kerja ini menggunakan pendekatan Actor Network Theory untuk melihat hubungan antara actor dalam penerapan teknologi informasi sehingga system informasi yang dihasilkan dapat diterima dan sesuai dengan bisnis proses yang ada pada universitas universal. Hasil dari penelitian ini adalah sebuah kerangka pikir untuk pembuatan system informasi berdasarkan hasil analisis ANT berbasis web.
\end{abstract}

Kata kunci: actor network theory; audit; iaps 4.0; kerangka kerja ti; mutu internal PT 


\section{PENDAHULUAN}

Perkembangan teknologi informasi semakin luas. Hal ini menuntut berbagai macam lini aktivitas untuk ikut memanfaatkan kemampuan teknologi yang mampu memantau data dan aktifitas secara transparan. Perubahan terhadap aturan perundang-undangan pada Peraturan Badan Akreditasi Nasional Perguruan Tinggi No 2 Tahun 2019 mengenai Panduan Penyusunan Laporan Evaluasi Diri dan Panduan Penyusunan Laporan Kinerja Program Studi Dalam Instrumen Akreditasi Program Studi [1]. Melihat adanya peran Instrumen Akreditasi Program Studi (IAPS 4.0) maka, kedepannya peran PD DIKTI semakin tinggi. Proses akreditasi oleh BAN-PT sudah tidak wajib untuk melakukan visit, kecuali ada yang ingin di konfirmasi kepada pihak terkait. Hal ini menunjukkan bahwa peran Teknologi mampu memberikan data dan informasi yang terpercaya. Dalam hal ini, pangkalan data PD DIKTI sangat penting.

Fungsi Lembaga Penjaminan $\mathrm{Mu}-$ tu (LPM) perguruan tinggi harus berjalan secara konsisten. Mengingat siklus SPMI berupa Penetapan, Pelaksanaan, Evaluasi, Pengendalian dan Peningkatan (PPEPP). Pada proses evaluasi dilakukan Audit Mutu Internal (AMI) perguruan tinggi[2]. Audit internal menggambarkan ruang lingkup audit. Audit internal merupakan suatu proses penilaian yang dilaksanakan berdasarkan prosedur dan standar perguruan tinggi secara objektif terhadap kegiatan operasional dan keberagaman kontrol yang ada didalam perguruan tinggi. Audit mutu internal dilaksanakan oleh auditor internal yang ditunjuk dan ditugaskan secara resmi oleh pimpinan tertinggi. Proses audit yang dilaksanakan oleh perguruan tinggi harus terdokumentasi dengan baik dan benar untuk menen- tukan suatu bukti dan objektifitas penilaian. Bukti dan proses yang terjadi dalam siklus PPEPP akan mendukung Instrumen Akreditasi Program Studi (IAPS) yang terdiri dari evaluasi diri, Laporan Kinerja Program Studi (LKPS) dan Laporan Kinerja Perguruan Tinggi (LKPT). Proses akreditasi benar-benar transparan, efektif dan efisien. Namun apabila perguruan tingggi tidak sanggup untuk mengikuti instrumen yang diberlakukan maka sanksi terberat bisa diberlakukan, misalnya perguruan tinggi di merger.

Untuk membantu perguruan tinggi dalam menghadapi Standar Penjaminan Mutu Eksternal (SPME) dalam tahapan Evaluasi, Penetapan dan Pemantauan (EPP) terkait IAPS maka, diperlukan suatu persiapan terkait teknologi informasi. Berupa pembangunan kerangka kerja teknologi informasi untuk audit mutu internal berbasis IAPS 4.0. [3]. Penelitian ini bertujuan untuk membangun suatu kerangka kerja sistem berdasarkan kebutuhan pengguna. Sehingga, menghasilkan kerangka kerja sistem yang tepat guna. Penelitian terdahulu yang sudah pernah dilakukan berbasis SN DIKTI belum berbasis IAPS 4.0 berdasarkan peraturan perundang-undangan yang berlaku saat ini mulai 25 maret 2019.

Kerangka kerja yang dibuat menggunakan metode actor network theory (ANT) yang digunakan untuk mendeskripsikan aktor; aktan; translasi yang meliputi problematisasi, interessement, enrollment dan mobilisasi jaringan secara umum dalam perancangan sistem informasi audit mutu internal berbasis IAPS 4.0. Actor Network Theory adalah pendekatan antarbidang studi pada ilmu sosial dan teknologi informasi. ANT dianggap cocok untuk menjelaskan kaitan antara artefak dan konteks sosial, termasuk proses 
penyesuaian antara karakteristik teknologi dan kemauan manusia. Dengan teori ini, maka semua aktor, baik dari pihak artefak maupun dari pihak pengguna, dimasukkan dalam faktor analisis [4]. ANT juga dapat membantu dalam memahami bagaimana ide, nilai, atau norma yang ada tertanam di dalam sebuah teknologi [5].

\section{METODE}

Tahapan yang dilakukan dalam pembangunan kerangka kerja system, terdiri dari beberapa tahapan. sebagaimana terlihat pada Gambar 1 .

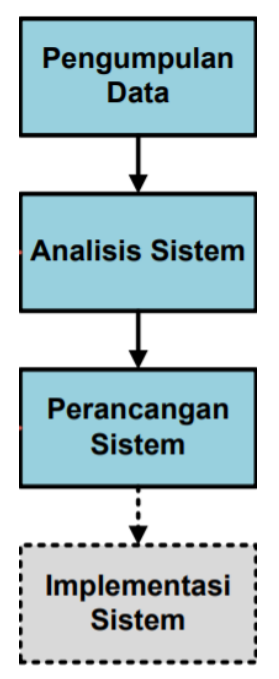

Gambar 1. Bagan Alir Penelitian

Berdasarkan pada gambar 2 tahapan penelitian dilakukan dengan menggunakan teknik pengumpulan data berupa studi literatur, wawancara dan observasi kepada pihak terkait yaitu kepala (Lembaga Penjaminan Mutu) LPM Universitas Universal. Kemudian data yang diperoleh di analisis lebih lajut berdasarkan kebutuhan pengguna sistem. Setelah melakukan analisis maka tahap berikutnya yaitu membangun kerangka kerja sistem untuk mempermudah dalam mengembangkan inovasi terhadap sistem berbasis IAPS 4.0. Metode dalam penelitian ini dilakukan dengan teknik pengumpulan data. Teknik pengumpulan data yang dilakukan diantaranya dengan pendekatan:

Studi literatur: Mempelajari peraturan dan undang-undang yang berlaku terkait audit mutu internal perguruan tinggi, Standar Penjaminan Mutu Internal (SPMI), artikel terkait dan penelitian terdahulu.

Wawancara: Pada tahapan ini dilakukan tanya jawab secara langsung dengan tim Lembaga Penjaminan Mutu (LPM) internal perguruan tinggi, para auditor dan para auditi yang terlibat dalam suatu lembaga yang memberlakukan proses audit. Pada tahapan ini juga akan dianalisis terkait actor, translasi dan intermediary yang terkait dalam jaringan pengembangan system informasi IAPS 4.0

Observasi: pada tahapan ini dilakukan dengan cara terjun langsung kelapan untuk melihat dan mendapatkan data lebih lanjut terkait audit mutu internal di perguruan tinggi[6].

\section{HASIL DAN PEMBAHASAN}

Untuk dapat membuat suatu kerangka kerja system teknologi informasi untuk audit mutu internal berbasis IAPS 4.0 maka terlebih dahulu perlu dipahami proses bisnis yang terjadi pada universitas universal. Hal ini penting dilakukan agar proses audit yang dilakukan sesuai dengan aturan dan prosedur kerja yang telah ditetapkan oleh system penjaminan mutu internal. Proses bisnis universitas universal dapat dilihat pada gambar 2 
DOI: https://doi.org/10.33330/jurteksi.v7i1.927

Available online at http://jurnal.stmikroyal.ac.id/index.php/jurteksi

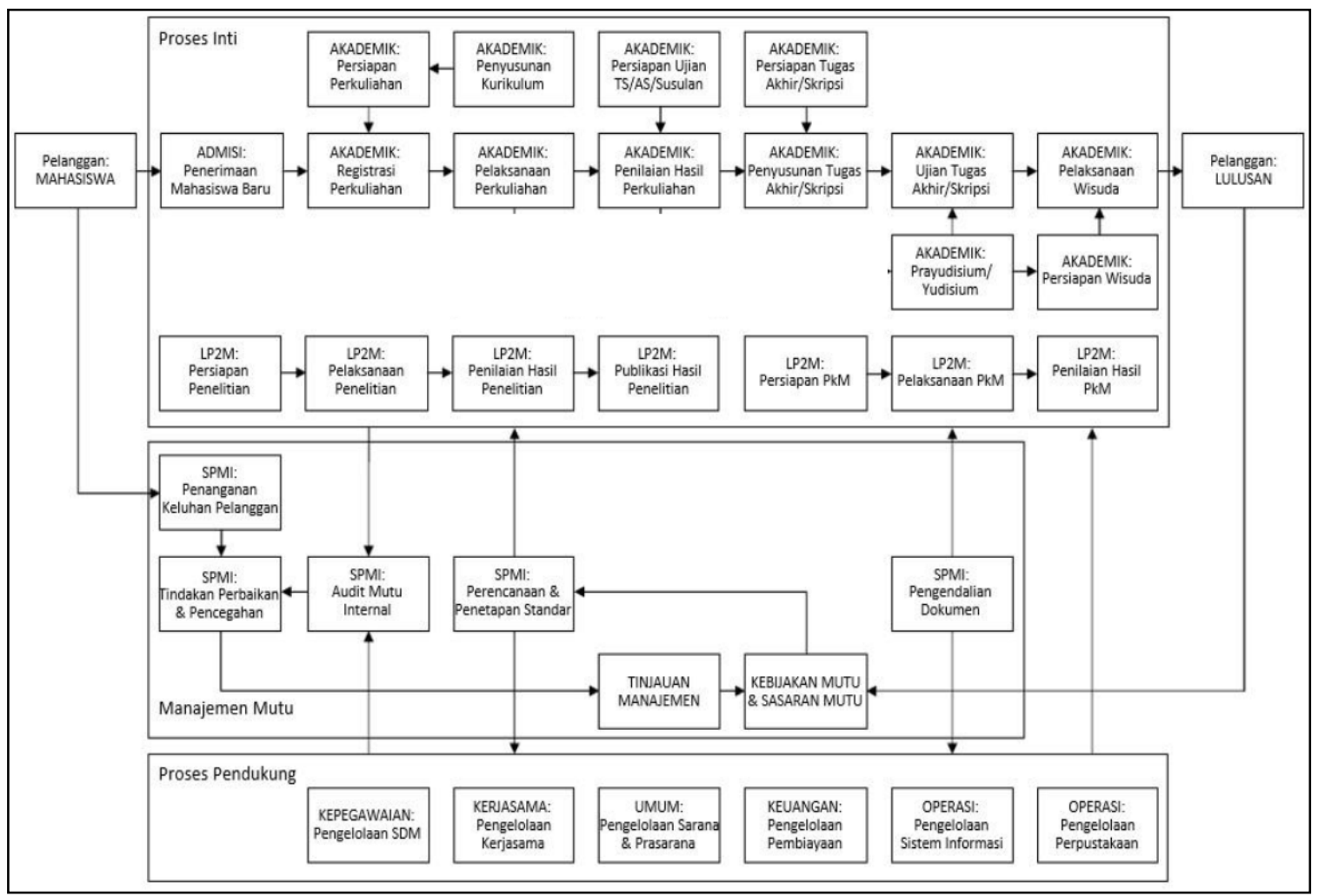

Gambar 2. Proses Bisnis Universitas Universal

Proses bisnis dibagi menjadi tiga bagian yaitu proses inti, manajemen mutu dan proses pendukung. Proses inti adalah sebuah proses persiapan dan pengelolaan pelanggan (mahasiswa) dari awal masuk hingga selesai. Proses ini dimulai dari penyusunan kurikulum dan kelengkapannya, proses admisi, proses perkuliahan, ujian dan skripsi dan wisuda. Untuk mendukung proses inti ini diperlukan manajemen mutu yang menjamin kelancaran dan keseuaian setiap proses yang dilakukan agar tidak melenceng dari aturan dan standar yang telah ditetapkan.

Proses kedua adalah manajemen mutu dimana dilakukan proses pengendalian mutu agar setiap proses yang dilakukan sesuai standard yang telah ditentukan. Proses ini sangat penting dan harus ada didalam suatu universitas demi terciptanya mutu lulusan yang sesuai dengan profil yang telah di rencanakan. Sedangkan proses pendukung merupakan proses yang mendukung proses inti dan manajemen mutu dalam hal pemenuhan kebutuhan proses pendidikan, penelitian dan pengabdian kepada masyarakat seperti kebutuhan kepegawaian, kerjasama, sarana dan prasaran serta sistem informasi dan perpustakaan [7].

Dari pemahaman proses bisnis tersebut maka berdasarkan konsep actor network theory perlu diidentifikasi actor apa saja yang terlibat dalam kerangka kerja teknologi informasi untuk audit mutu internal berbasis IAPS 4.0 agar system yang dirancang menjadi efisien dan sistematis seperti yang dijabarkan pada tabel 1[8]. 
DOI: https://doi.org/10.33330/jurteksi.v7i1.927

Available online at http://jurnal.stmikroyal.ac.id/index.php/jurteksi

Tabel 1. Identifikasi actor

\begin{tabular}{ll}
\hline \multicolumn{1}{c}{ Actor } & \multicolumn{1}{c}{ Tanggung Jawab dan Peran } \\
\hline SPMI & $\begin{array}{l}\text { Pengelola kebijakan dan standar dalam proses penjaminan mutu } \\
\text { universitas universal }\end{array}$ \\
\hline Auditor & $\begin{array}{l}\text { Pihak yang melakukan audit terhadap auditee. Auditor bisa teridiri dari } \\
\text { dosen, Koordinator program studi, dekan atau kepala unit seperti kepala }\end{array}$ \\
& $\begin{array}{l}\text { LPPM, direktur Akademik dan kemahasiswaan, kepegawaian, Kerjasama } \\
\text { dan operasional }\end{array}$ \\
\hline Auditee & $\begin{array}{l}\text { Pihak yang diaudit oleh auditor. Auditee merupakan unit pengelola } \\
\text { program studi termasuk coordinator program studi dan dekan fakultas }\end{array}$ \\
\hline Koordinator Audit & Pihak yang menjamin proses penyelenggaraan audit \\
\hline
\end{tabular}

Dari hasil identifikasi aktor pada tabel 1 menggunakan ANT yang digunakan untuk menentukan keterkaitan antara aktor, diperoleh konsep pengembangan teknologi informasi audit mutu interal berbasis IAPS 4.0 yang selanjutnya akan dibangun sistem berbasis web yang diimplementasikan menggunakan framework laravel, bootstrap dan Javascript yang disesuaikan dengan perencanaan kerangka pikir pada gambar 3 [9][10].

SPMI (PPEPP)

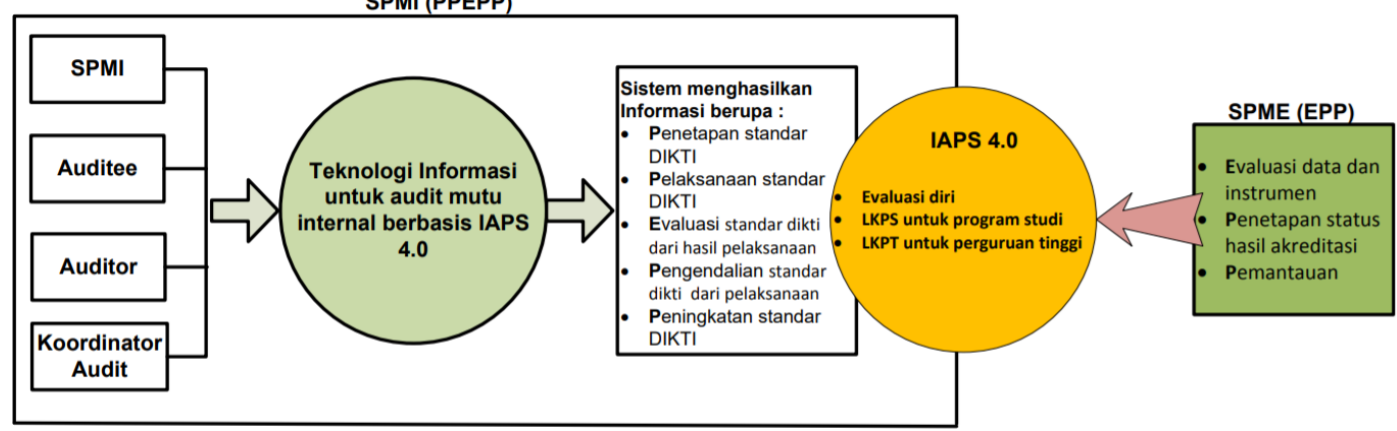

Gambar 3. Kerangka Pikir Sistem IAPS 4.0

Gambar 3 merupakan gambaran kerangka pikir mengenai kerangka kerangka kerja teknologi informasi untuk audit mutu internal berbasis IAPS 4.0. Instrumen Akreditasi Program Studi (IAPS 4.0) didukung oleh siklus SPMI yaitu PPEPP yang berjalan di dalam perguruan tinggi. SPME melalui siklus EPP, selalu melakukan pemantauan terhadap evaluasi diri, LKPS dan LKPT untuk Akreditasi perguruan tinggi. Kerangka pikir ini akan meng-hasilkan system informasi yang dapat mempermudah proses audit mutu internal berbasis IAPS 4.0 yang menghubungkan semua komponen yang ada didalam proses bisnis yang ada. Sehingga system ini dapat membantu mengisi data untuk laporan kinerja program studi (LKPS) dan laporan kinerja perguruan tinggi (LKPT) yang pada akhirnya mempermudah dalam pembuatan laporan evaluasi diri berdasarkan informasi yang dihasilkan oleh system ini.

\section{SIMPULAN}

Actor network theory digunakan untuk membantu mengetahui hubungan antara actor dalam proses bisnis yang ada pada universitas universal sehingga kerangka pikir yang dibuat menjadi mudah untuk diimplementasikan menjadi suatu system informasi yang terintegrasi 
dalam pelaksanaan system penjaminan mutu internal (SPMI). Setelah melakukan analisis dengan metode ANT proses berikutnya adalah membuat kerangka pikir dengan mengikuti panduan audit mutu internal berbasis IAPS 4.0 yang didukung oleh siklus SPMI yaitu PPEPP yang berjalan di dalam perguruan tinggi. Hasil dari penelitian ini adalah suatu kerangka pikir yang valid berdasarkan bisnis proses yang berjalan di universitas universal menggunakan metode Actor Network Theory. Kerangka pikir ini selanjutkan akan digunakan untuk membuat sistem informasi penjaminan mutu internal berbasis IAPS 4.0 yang terintegarasi disemua bagian didalam bisnis proses universitas universal yang berbasis web agar lebih fleksibel dan dapat diakses dari mana saja dan kapan saja.

\section{UCAPAN TERIMA KASIH}

Terima kasih kepada Kemenristekdikti (Kementerian Riset, Teknologi dan Pendidikan Tinggi) dan DRPM (Direktorat Riset dan Pengabdian Masyarakat) yang telah memberikan bantuan pendanaan dalam publikasi ilmiah ini.

\section{DAFTAR PUSTAKA}

[1] BAN-PT, "Peraturan Badan Akreditasi Nasional Perguruan Tinggi No 2 Tahun 2019." BAN-PT, 2019.

[2] A. Hendrawan and A. Yulianeu, "Sistem Penjaminan Mutu Internal (SPMI) (Di Akademik Kebidanan Respati Sumedang)," J. Manaj. Inform., vol. 4, no. 2, 2017.

[3] Adelin and H. Effendi, "Aplikasi
Audit Mutu Akademik Internal dengan Pendekatan Extreme Programming," J. TI Atma Luhur, vol. 4, no. 1, pp. 13-24, 2017.

[4] A. Nuryanto, "Keberhasilan Dan Dampak Penerapan Sistem Informasi Desa Dalam Perspektif Actor Network Theory ( Studi Kasus di Desa Ngumbul Kabupaten Pacitan )," Pros. Semin. Nas. Geotik 2019, no. March, pp. 65-76, 2019.

[5] A. Tatnall and A. Gilding, "ActorNetwork Theory and Information Systems Research," Proc. 10th Australas. Conf. Inf. Syst., no. January 1999, pp. 955-966, 1999

[6] A. N. Purbowo, "Analisa dan Pengembangan Tools Internal Audit Pada Institut Tenologi Sepuluh Nopember," J. Ilm. Inst. Teknol. Sepuluh Novemb., 2010.

[7] V. Rindengan, A. Lumenta, and Y. Rindengan, "Rancang Bangun Aplikasi Audit Mutu Akademik Internal Universitas Sam Ratulangi Berbasis Web," J. Tek. Inform., vol. 6, no. 1, pp. 1-6, 2015,

[8] R. Sidik, M. Fitriawati, S. Mauluddin, and A. Nursikuwagus, "Model Penerapan Algoritma Ant Colony Optimization (Aco) Untuk Optimasi Sistem Informasi Penjadwalan Kuliah," J. Teknol. dan Inf., vol. 8, no. 2, 2018,

[9] A. Komarudin and T. H. Pudjiantoro, "Sistem Informasi Audit Mutu Internal Satuan Penjaminan Mutu (SPM) Unjani," SEINASI-KESI, pp. 76-81, 2018.

[10] H. B. Seta, I. N. Isnainiyah, and T. Wati, "Implementasi Actor Network Theory(ANT) Framework Untuk Rancangan Data Visualization Pada Perpustakaan Universitas," Pros. SINTAK 2017, pp. 359-364, 2017. 